\title{
Female Inguinal Hernia - Conservatively Treated as Labial Swelling for a Long Time-A Case Report
}

\author{
Shabnam N $N^{\mathrm{a}}$, Alam $\mathrm{H}^{\mathrm{b}}$, Talukder MRH' ${ }^{\mathrm{c}}$, Humayra ZU' ${ }^{\mathrm{d}}$, Ahmed AHMT
}

\begin{abstract}
Inguinal hernia in females is quite uncommon compared to males. However, in female it may pose both a diagnostic as well as surgical challenge to the attending surgeon. Awareness of anatomy of the region and all the possible contents is essential to prevent untoward complications. Here we are presenting a case of indirect inguinal hernia in a 25 years old women and how she was diagnosed and ultimately managed.
\end{abstract}

Key words: Inguinal hernia, females

(BIRDEM Med J 2018; 8(1): 81-82)

\section{Introduction}

Inguinal hernia in female is relatively uncommon as compared to males. The incidence of inguinal hernia in females is $1.9 \%^{1}$. Obesity, pregnancy and operative procedures have been shown to be risk factors that commonly contribute to the formation of inguinal hernia $^{2}$. Surgical management in women is similar to that in men. However a wide variety of presentations may add to the confusion in diagnosing inguinal hernia in females. Surgical repair of the hernia in women needs a proper understanding of the relationship of the reproductive organs to the hernia site.

A case of indirect inguinal hernia in a 25 -year-old women is presented along with a brief review of the surgical management.

\section{Author Information}

a. Dr. Nilufar Shabnam, MBBS, FCPS (Surgery), MRCS (Edin), MRCPS (Glasgow), Registrar, Department of Surgery, IMC \& BIRDEM

b. Dr. Hasina Alam, MBBS, FCPS (Surgery), Registrar, Department of Surgery, IMC \& BIRDEM

c. Dr. Md. Rajibul Haque Talukder, MBBS, FCPS (Surgery), Registrar, Department of Surgery, IMC \& BIRDEM

d. Dr. Zaman Ummay Humayra, MBBS, FCPS (Plastic Surgery), Registrar, Department of Surgery, IMC \& BIRDEM

e. Dr. A.H.M. Tanvir Ahmed, MBBS, FCPS (Surgery), Registrar, Department of HBP Surgery, IMC \& BIRDEM

Address of Correspondence: Dr. Nilufar Shabnam, Registrar, Department of Surgery and MISC, BIRDEM \& Ibrahim Medical College, Dhaka, Bangladesh, E mail: nilufarshabnam@ yahoo.com Received : January 30, 2017 Accepted: October 31, 2017

\section{Case Report}

A 25-year-old female, non obese, mother of one child, delivered vaginal (NVD) presented with a swelling in the left groin for 7 years. Initially she presented to different gynecologists with labial swelling. They treated her conservatively. As she was not improving, she finally presented to surgeon. She gave history of left groin swelling extending down to labia majora which initially appeared during straining but later on it persisted all the time. In lying position, the swelling disappeared. Patient did not give any history of chronic cough, constipation or repeated pregnancy. Physical examination revealed left inguinal swelling extending to labia majora, cough impulse was positive, the swelling was reducible, deep ring occlusive test was positive. Patient was provisionally diagnosed as left sided indirect complete reducible inguinal hernia. Proper counseling was done for open hernioplasty under spinal anaesthesia.

During operation inguinal canal was opened, the sac was identified, dissected free from the round ligament up to deep ring, opened and reduction of omentum was ensured (Figure-1). The round ligament was carefully preserved (Figure-2). A prolyprolene mesh was placed over the posterior wall and fixed with prolyprolene sutures. External oblique aponeurosis was closed with 2-0 vicryl and skin was closed with 4-0 prolyprolene sutures. Post operative recovery was uneventful. Skin stitches were removed on $8^{\text {th }}$ post operative day. Patient has been following up for more than six months with no recurrence. 


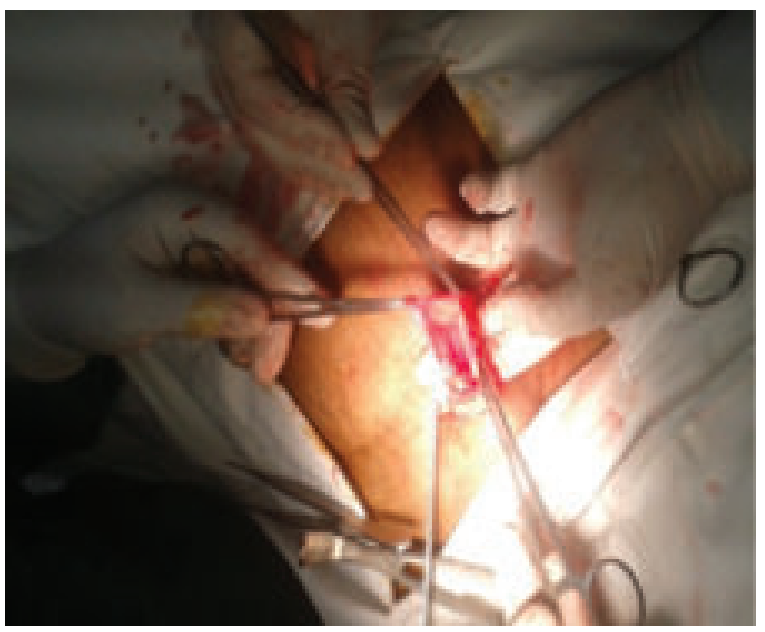

Figure 1. Intraoperative photograph of inguinal hernia showing opened hernia sac

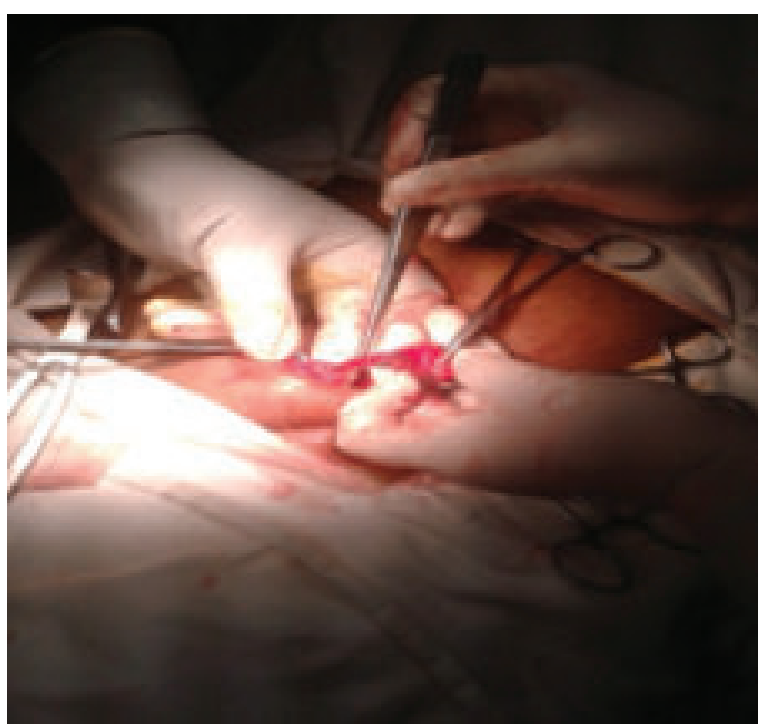

Figure 2. Photograph showing round ligament marked by tooth forceps.

\section{Discussion}

Inguinal hernias in female are usually of indirect variety. These case can be very deceptive. Endometriosis can develop in a hernia sac giving rise to a magnitude of confusing symptoms. ${ }^{3,4}$ Understanding the anatomy of female inguinal canal is pivotal for successful outcome of the surgical repair.

Female inguinal hernia structurally is similar to that in male with the exception of contents. In female, round ligament replaces the cord. The round ligament is an important support of the uterus. Transection of round ligament during repair can lead to anatomical weakening of uterine support. Surgeons are in favour of its removal in order to ensure the complete obliteration of the inguinal canal in order to reduce the chances of recurrence. ${ }^{5,6}$ In our case, we preserved the round ligament

A wide variety of contents can surprise the surgeon at the time of surgery. Sliding inguinal hernia may contain the ovary, part of the uterus, fallopian tube. ${ }^{7,8}$ Therefore the hernia sac in a female patient is like a magic box, the truth of which is revealed only after exploration. In this case, content of the sac was omentum.

Use of local tissue to strengthen the posterior wall may not be worthwhile. ${ }^{9}$ It is safe practice to place a mesh over the posterior wall. Laparoscopic approach can also be used to treat this condition.

\section{Conclusion}

Inguinal hernia in females though rare, is not impossible. An intuitive mind and careful clinical examinational can lead to diagnosis. Awareness of female inguinal anatomy is essential before embarking on any surgical intervention. The round ligament should be preserved as far as possible to prevent any weakening of uterine support.

Conflict of interest: Nothing to declare.

\section{References}

1. Read RC, White JJ. Inguinal herniation. Am J Surg 1978; 136:651-57.

2. Ponka JL. Hernias of abdominal wall. Miami. WB Saunders: Philadelphia;1980:82-90.

3. Sataloff DM, La Vorgna KA, MeFarland MM. Extrapelvic endometriosis presenting as a hernia: clinical reports and review of litature. Surgery. 1989:105:102-12

4. Kamio M, Nagata T, Yamasaki H, Yoshinaga M, Douchi T Inguinal hernia containing functioning rudimentary uterine horn and endometriosis. Obstet Gynecol 2009;113:563-66.

5. Herrington JK. Occult inguinal hernia in the female. Ann Surg 1975;181:481-83

6. Ando H, Kaneko K, Ito F, Seo T, Ito T. Anatomy of the round ligament in female infants and children with an inguinal hernia. Br J Surg 1997;84:404-5.

7. Osifo OD, Ovueni ME. Inguinal herhia in Nigarian female children: beware of ovary and fallopian tube as contents. Hernia 2009;13:149-53.

8. Ozkan OV, Semerci E, Asian E, Ozkan S, Dolapcioglu K, Besirov E. A right sliding indirect inguinal hernia containing paraovarian cyst. Fallopian tube and ovary: a case report. Arch Gynecol Obstet 2009;279:897-99.

9. Glasgow F. An evaluation of the strength of the posterior wall of the inguinal canal in woman. Br J Surg 1973;60:342-44. 